\title{
Risk of subsequent primary malignancies among patients with prior colorectal cancer: a population-based cohort study
}

This article was published in the following Dove Press journal:

OncoTargets and Therapy

13 March 2017

Number of times this article has been viewed

\author{
Jiao Yang' \\ Shuting $\mathrm{Li}^{\prime}$ \\ Meng L $v^{\prime}$ \\ Yinying $\mathrm{Wu}^{\prime}$ \\ Zheling Chen' \\ Yanwei Shen' \\ Biyuan Wang' \\ Ling Chen' \\ Min $\mathrm{Yi}^{1,2}$ \\ Jin Yang'
}

'Department of Medical Oncology, First Affiliated Hospital of Xi'an Jiao Tong University, Xi'an, People's Republic of China; ${ }^{2}$ Department of Breast Surgical Oncology, University of Texas MD Anderson Cancer Center. Houston, TX, USA
Correspondence: Jin Yang Department of Medical Oncology, First Affiliated Hospital of Xi'an Jiao Tong University, 277 Yanta West

Road, Xi'an, Shaanxi 71006I, People's

Republic of China

Tel/fax +862985323422

Email 1473106133@qq.com
Background: The site-distribution pattern and relative risk of subsequent primary malignancies (SPMs) in colorectal cancer (CRC) patients remains to be determined.

Materials and methods: A population-based cohort of 288,390 CRC patients diagnosed between 1973 and 2012 from the Surveillance, Epidemiology, and End Results database was retrospectively reviewed. Standardized incidence ratios were calculated to estimate the relative risk for SPMs.

Results: The overall risk of SPMs increased in CRC patients (standardized incidence ratio 1.02 ) in the first 5 years after CRC diagnosis compared with that in the general population, and was negatively related to age at diagnosis. Risk increased significantly for cancers of the small intestine, ureter, colorectum, renal pelvis, endocrine system, and stomach, and decreased significantly for cancers of the gallbladder, liver, myeloma, and brain, as well as lymphoma. Patients with different prior CRC subsites showed specific sites at high risk of SPM. Prior right-sided colon cancer was associated with cancers of the small intestine, ureter, renal pelvis, thyroid, stomach, pancreas, and breast and prior left-sided colon cancer associated with secondary CRC, whereas rectal cancer was associated with cancers of the vagina, urinary bladder, and lung.

Conclusion: Risk of SPMs increases in CRC survivors, especially in the first 5 years after prior diagnosis. Intensive surveillance should be advocated among young patients, with specific attention to the small intestine, colorectum, renal pelvis, and ureter. The common sites at high risk of SPM originate from the embryonic endoderm. Genetic susceptibility may act as the main mechanism underlying the risk of multiple cancers.

Keywords: colorectal cancer, multiple primary malignancies, SEER, standard incidence ratio, cancer risk

\section{Introduction}

Colorectal cancer (CRC) is the third-commonest cancer worldwide and the second-commonest cause of cancer-related death in Western countries. ${ }^{1}$ Since the widespread adoption of screening methods, including colonoscopy and fecal occult blood test, an increasing number of CRC patients are being diagnosed with localized disease. $^{2}$ Curative surgery for CRC patients with limited metastases in the liver or with solitary metastasis in the lung can be successfully performed by multidisciplinary teams. ${ }^{3}$ Targeted treatment also considerably improves the survival of CRC patients with distant metastases. ${ }^{4}$ A long life exposes these survivors to the possibility of developing secondary or additional primary malignancies.

Studies have found that patients previously diagnosed with $\mathrm{CRC}$ are at higher risk of second primary CRCs than the general population. ${ }^{5-7}$ Synchronous colorectal 
adenoma and a family history of CRC are risk factors for developing a second primary CRC. ${ }^{8-10}$ From a clinical perspective, subsequent primary malignancies (SPMs) may occur in any organ of the human body besides the part of the colorectum resected by prior surgery. The aim of the present study was to clarify the unique site-distribution pattern and relative risk of SPMs among CRC survivors and to identify patients who are at increased risk of developing SPMs.

\section{Materials and methods}

\section{Data source}

The National Cancer Institute's Surveillance, Epidemiology, and End Results (SEER) program database was used to identify the cohort of patients analyzed in the present study. SEER currently collects cancer-incidence and -survival data from population-based cancer registries covering approximately $30 \%$ of the US population (http://seer.cancer.gov). The SEER data contain no identifiers, and are publicly available for cancer-epidemiology and health-service research studies. The population-based SEER database has a well-defined data collection and extensive quality standards to ensure that the information is accurate. Permission to access the research data was obtained. The study was approved by the review board of the First Affiliated Hospital of Xi'an Jiao Tong University. The SEER 9 registry data, including individual data from 1973 to 2012 from nine registries (Atlanta, Connecticut, Detroit, Hawaii, Iowa, New Mexico, San Francisco-Oakland, Seattle-Puget Sound, and Utah), were used by the SEER Stat software to estimate the standardized incidence of SPMs in CRC cases.

\section{Study population}

The specific inclusion criteria were as follows: patients diagnosed with prior cancer between 1973 and 2012; site record ICD-O-3/WHO 2008 limited to colon and rectum; and histological type ICD-O-3 limited to adenocarcinoma (8140). Patients were excluded if documentation of age at diagnosis was lacking or if it was reported only on the death certificate or autopsy. Patients diagnosed with CRC were followed until their death or the 2012 year's end. Information on SPM development was documented. SPM required a minimum latency period of 6 months after the prior CRC diagnosis to exclude synchronous primary malignancies (PMs). Therefore, participants who were followed $<6$ months or had SPMs diagnosed within the first 6 months after the diagnosis of CRC were not enrolled. Information on age of diagnosis with prior CRC, sex, latency period, sites of SPM, and location of index $\mathrm{CRC}$ was extracted from the database.
The cohort consisted of 233,890 patients who were diagnosed with primary pathologically confirmed adenocarcinoma of the colorectum.

\section{Statistical analysis}

Multiple primary standardized incidence ratios (SIRs) were calculated using SEER Stat software version 8.2.1 to determine the relative SPM risk among this cohort. The SIR represents the ratio of the observed to the expected number of incident-cancer cases based on the corresponding segment of the US general population according to age in 5-year intervals, sex, and calendar year by the specific stratified person-time variable accrued from the CRC cohort. Data on cancer incidence among the general population were retrieved from SEER 9 Regs Research Data Nov 2014 Sub. More detailed information on both SEER Stat software and the method the software uses to derive the SIRs is available on the SEER-registry website (http://seer.cancer.gov/seerstat). SIRs were determined for subgroups defined by age, latency, and sex. Additionally, cases were stratified according to the anatomic subsite of prior CRC into three groups: right-sided colon cancer, left-sided colon cancer, and rectal cancer. The right-sided colon cancer group included cancers emerging at bowel segments between the cecum and the transverse colon, whereas the left-sided colon cancer group included cancers occurring at bowel segments between the splenic flexure and the rectosigmoid junction. In further stratified analyses according to tumor location, sex, and age, all patients were grouped into two groups according to age: $<60$ and $\geq 60$ years. Evaluation of the confidence intervals (CIs) of SIRs was used to determine any overlap.

\section{Results}

Based on the aforementioned criteria, 33,047 SPMs were identified in 28,863 CRC patients from the SEER database, including 16,618 (57.6\%) men and 12,245 (42.4\%) women, with a median age of 68 years at the time of diagnosis (interquartile range 60-75 years) (Table 1). A total follow-up time of 1,628,144 cumulative person-years at risk was calculated, with a mean of 6.97 person-years at risk.

Compared with the incidence in the general population, CRC patients had a higher overall risk of SPM (SIR 1.02, 95\% CI 1.01-1.03), especially for solid tumors (SIR 1.05, 95\% CI 1.04-1.06) (Figure 1). The risk increased mainly for cancers of the small intestine (SIR 3.09), ureter (SIR 1.5), colorectum (SIR 1.47), renal pelvis (SIR 1.27), endocrine system (SIR 1.2), and stomach (SIR 1.15). Conversely, risk decreased significantly for the gallbladder (SIR 0.68), liver (SIR 0.71), 
Table I Baseline characteristics of patients with subsequent primary malignancies development after colorectal cancer

\begin{tabular}{|c|c|}
\hline Characteristic & Total $(n=28,863)$ \\
\hline \multicolumn{2}{|l|}{ Sex } \\
\hline Female, n (\%) & I2,245 (42.4) \\
\hline Male, n (\%) & $16,618(57.6)$ \\
\hline \multicolumn{2}{|l|}{ Age at diagnosis (years) } \\
\hline Median (range) & $68(14-102)$ \\
\hline$\leq 50, \mathrm{n}(\%)$ & $1,992(6.9)$ \\
\hline $5 \mathrm{I}-60, \mathrm{n}(\%)$ & $5,28 \mid(\mid 8.3)$ \\
\hline $6 \mathrm{I}-70, \mathrm{n}(\%)$ & $9,864(34.2)$ \\
\hline $7 \mathrm{I}-80, \mathrm{n}(\%)$ & $8,788(30.4)$ \\
\hline $80+, \mathrm{n}(\%)$ & $2,938(10.2)$ \\
\hline \multicolumn{2}{|l|}{ Year of diagnosis } \\
\hline 1973-1985, n (\%) & II,07| (38.3) \\
\hline 1986-1999, n (\%) & $12,406(43)$ \\
\hline 2000-20I2, n (\%) & $5,386(\mid 8.7)$ \\
\hline \multicolumn{2}{|l|}{ Race } \\
\hline White, n (\%) & $24,848(86.1)$ \\
\hline Black, n (\%) & $2,125(7.4)$ \\
\hline Others, n (\%) & $\mathrm{I}, 890(6.5)$ \\
\hline \multicolumn{2}{|l|}{ SEER summary stage } \\
\hline Localized, n (\%) & $13,452(46.6)$ \\
\hline Regional, n (\%) & I3,539 (46.9) \\
\hline Distant, n (\%) & $\mathrm{I}, \mathrm{I} 05(3.8)$ \\
\hline Unstaged, n (\%) & $767(2.7)$ \\
\hline \multicolumn{2}{|l|}{ Tumor grade } \\
\hline I, n (\%) & $3,486(12.1)$ \\
\hline II, n (\%) & I7,079 (59.2) \\
\hline III, n (\%) & $3,952(13.7)$ \\
\hline Undifferentiated, n (\%) & $20 \mathrm{I}(0.7)$ \\
\hline Unknown, n (\%) & $4,145(14.3)$ \\
\hline \multicolumn{2}{|l|}{ Primary tumor location } \\
\hline Right colon, n (\%) & $8,674(30.1)$ \\
\hline Left colon, n (\%) & $\mid 4,907(5 \mid .6)$ \\
\hline Rectum, n (\%) & $4,995(17.3)$ \\
\hline Large bowel, nonspecific, n (\%) & $287(\mathrm{I})$ \\
\hline
\end{tabular}

Abbreviation: SEER, Surveillance, Epidemiology, and End Results.

myeloma (SIR 0.78), brain (SIR 0.85), and lymphoma (SIR 0.92) compared with the general population.

Most of the increased risk was concentrated in the initial 5 years after primary diagnosis (Figure 2). The risk increased progressively for all solid tumors in the second 5 years. After 10 years, the risk decreased for SPMs of all sites, becoming similar to that in the general population for all solid tumors.

A strong inverse relationship was observed between SIRs and age at primary CRC diagnosis (Figure 3). SIRs for all SPMs according to age-group were 8.3 for $<35$ years, 3.47 for 40-44 years, 2.28 for 45-49 years, 1.81 for 50-54 years, 1.49 for 55-59 years, 1.15 for 60-64 years, 1.02 for 65-69 years, 0.99 for $70-74$ and $75-79$ years, 0.98 for $80-84$ years, and 0.9 for patients $\geq 85$ years.

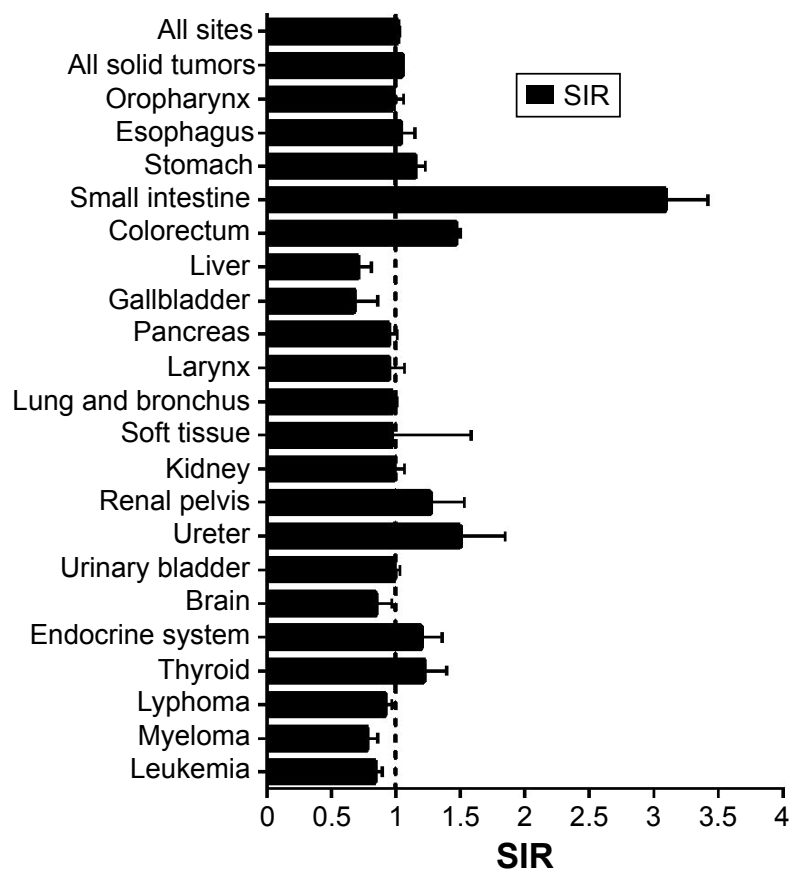

Figure I Site distribution of subsequent primary malignancies.

Notes: The dashed vertical reference line (SIR I) indicates similar risk of subsequent primary malignancies compared with the general population. The error bars indicate the $95 \%$ confidence interval of SIR. The risk increased mainly for subsequent primary cancers of the small intestine, ureter, colorectum, renal pelvis, endocrine system, and stomach (all SIRs >I), but decreased for the gallbladder, liver, myeloma, and brain, as well as lymphoma compared with the general population (all SIRs $<$ I).

Abbreviation: SIR, standardized incidence interval.

The overall risk for SPMs was higher in women with CRC (SIR 1.07, 95\% CI 1.06-1.09) and lower in men with CRC (SIR 0.98, 95\% CI 0.97-0.99) than in the general population (Figure 4). The risk increased consistently for the stomach, small intestine, colorectum, ureter, and the endocrine system, and decreased consistently for the liver, gallbladder, brain, and hematological malignancies in women and men. The relative risks for several cancers differed between men and women. Compared with the general population, lung cancer was more frequent in women with CRC and less frequent in men with CRC. The risk of prostate cancer increased in men, whereas in women the risk of uterine and vaginal cancer increased and that of ovarian cancer decreased.

There was an inverse relationship between the overall SIRs and the subsites of primary diagnosis: 1.09 in rightsided colon cancer, 1 in left-sided colon cancer, and 0.93 in rectal cancer. There were significant differences in the risk estimates for various malignancies among the three subsite groups (Figure 5). For right-sided colon cancer survivors, cancer risk was highest for the small intestine, ureter, renal pelvis, thyroid, stomach, pancreas, and breast; in left-sided colon cancer patients, risk was highest for the colorectum; and in rectal cancer patients risk was highest 


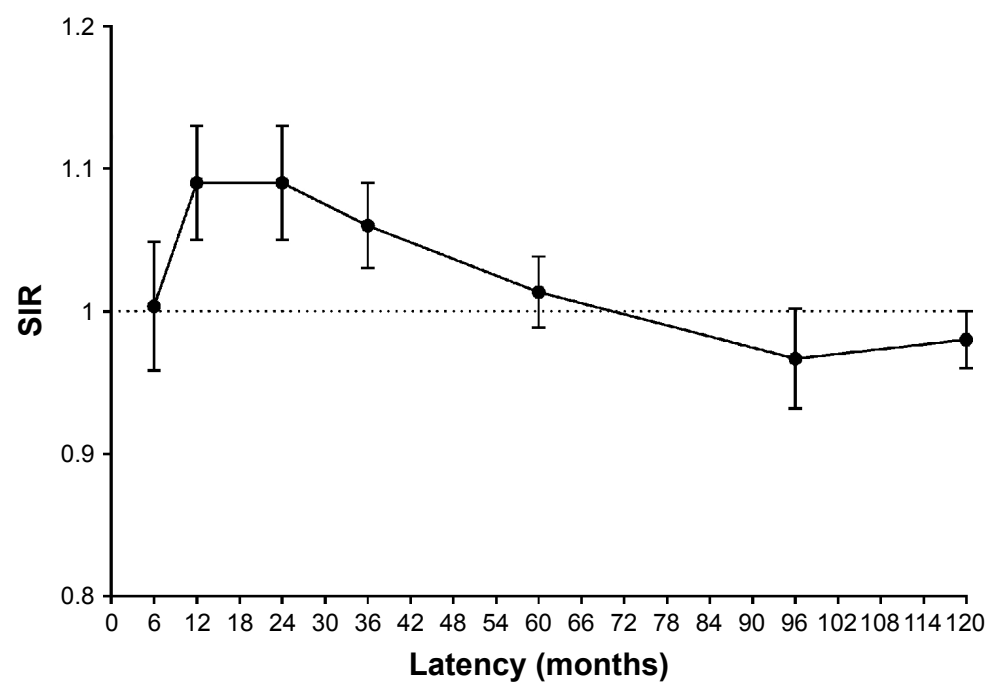

Figure 2 Risk varied by latency for subsequent primary malignancies in all sites. Note: Overall risk increased mainly in the initial 5 years after primary diagnosis. Abbreviation: SIR, standardized incidence interval.

for the vagina, urinary bladder, and lung. On the other hand, cancer risk decreased for the liver, ovary, prostate, pancreas, leukemia, and myeloma in rectal cancer survivors; and decreased for the brain, gallbladder, lymphoma, lung, urinary bladder, and breast in left-sided colon cancer survivors. Stratified analyses (Table 2) indicated that the risk of all SPMs increased (SIR >1) in young patients, women, or patients with right-sided colon cancer within each subgroup.

\section{Discussion}

Improvements in the survival of CRC patients have led to several studies investigating second primary tumors in the

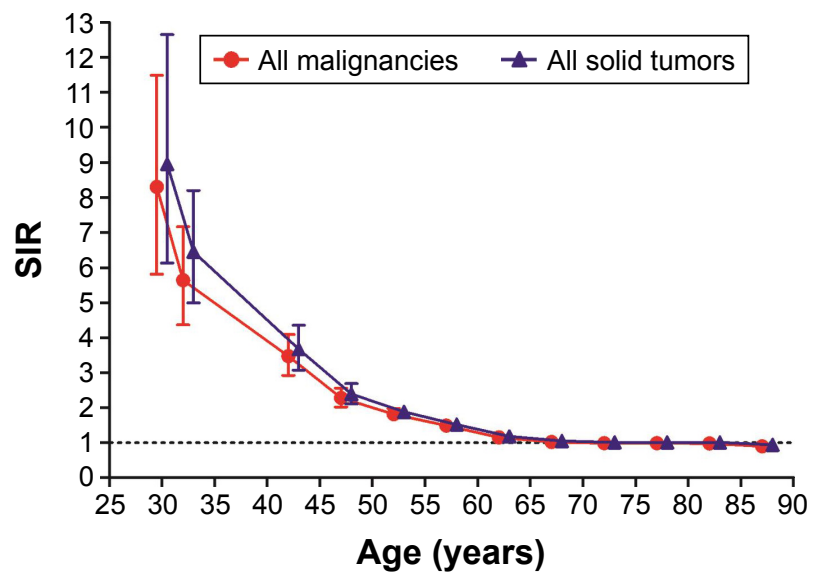

Figure 3 Risk varied by age for subsequent primary malignancies of all sites and all solid tumors.

Note: A strong inverse relationship was observed between SIR and age of primary colorectal cancer diagnosis.

Abbreviation: SIR, standardized incidence interval. survivors: ${ }^{11-13}$ however, there are few studies focusing on all SPMs in all possible sites. The results of the current study indicated that CRC survivors have a $\%$ higher overall risk of developing SPMs than the general US population. Lee et al found a $13 \%$ higher risk for secondary primary cancer in CRC survivors in Taiwan. ${ }^{11}$ Although the reasons for the differences in relative risk are not clear, they may be attributed in part to the different populations included in the SEER and the Taiwanese cohort. Different incidence rates were reported for each PM in different populations. ${ }^{14,15}$ Regarding secondary primary CRC, the cumulative incidence rate of $12 \%$ observed in the present study was considerably higher than the $3 \%-6.3 \%$ rate reported in previous studies. ${ }^{16,17}$ The difference could be attributed to the fact that the current study involved all the SPMs related to all body sites besides secondary cancer located at the residual part of the colorectum, as well as a much longer follow-up duration. The risk of SPMs increased with time from the diagnosis of primary CRC, mostly in the first 5 years. According to the current National Comprehensive Cancer Network guidelines, CRC patients should be screened regularly for disease recurrence or metastasis. The results of the present study support an intensive follow-up strategy in the first 5 years for CRC patients and highlight the possibility of SPM occurrence. In addition, the risk of subsequent CRC increased more obviously in patients with left-sided colon cancer, followed by those with right-sided colon cancer and rectal cancer; therefore, colonoscopy surveillance is especially important in these patients during their follow-up visits. 


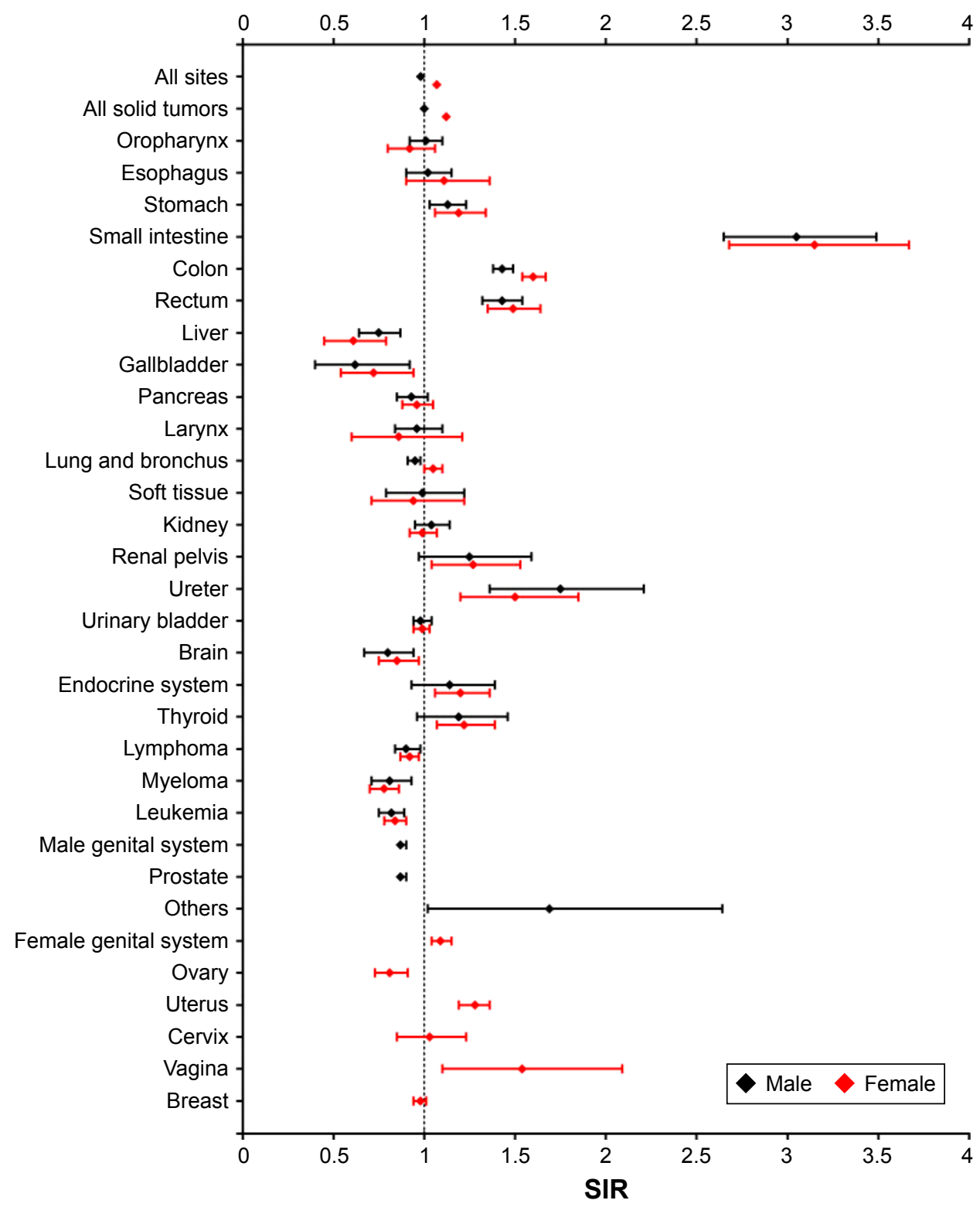

Figure 4 Risk varied by sex for subsequent primary malignancies in different sites.

Note: Overall risk for subsequent primary malignancies and sites at high cancer risk were different between women and men with prior colorectal cancer.

Abbreviation: SIR, standardized incidence interval.

The lower the age of patients at the time of diagnosis of primary CRC, the higher the risk of developing SPMs, with an SIR $>5$ in patients 40 years or younger and an SIR of 2.6 in patients $<50$ years. In an earlier study, old patients were found to be at higher risk than young patients. ${ }^{11}$ Age $\geq 70$ years was even considered an independent predictor for second primary cancer. However, the present study indicated high risk in young patients, in agreement with most previous studies, ${ }^{12,18,19}$ and this risk existed regardless of sex and prior tumor location. CRC patients aged $\leq 50$ years, especially those with a positive family history, were at higher risk of secondary primary cancers, suggesting that they should be screened for hereditary CRC.

Lynch syndrome was associated with an increased risk of certain malignancies in the colorectum, uterus, ovary, stomach, small intestine, urine epithelial tissues, central neural system, pancreas, and breast, whereas familial adenomatous polyposis was associated with a high tendency to develop cancers derived from the thyroid and duodenum. ${ }^{20-24}$ The current study indicated that the risk of cancer was high for the small intestine, colorectum, uterus, renal pelvis, thyroid, and stomach in CRC survivors, especially in young patients, whereas it was low for cancers of the gallbladder, liver, and 


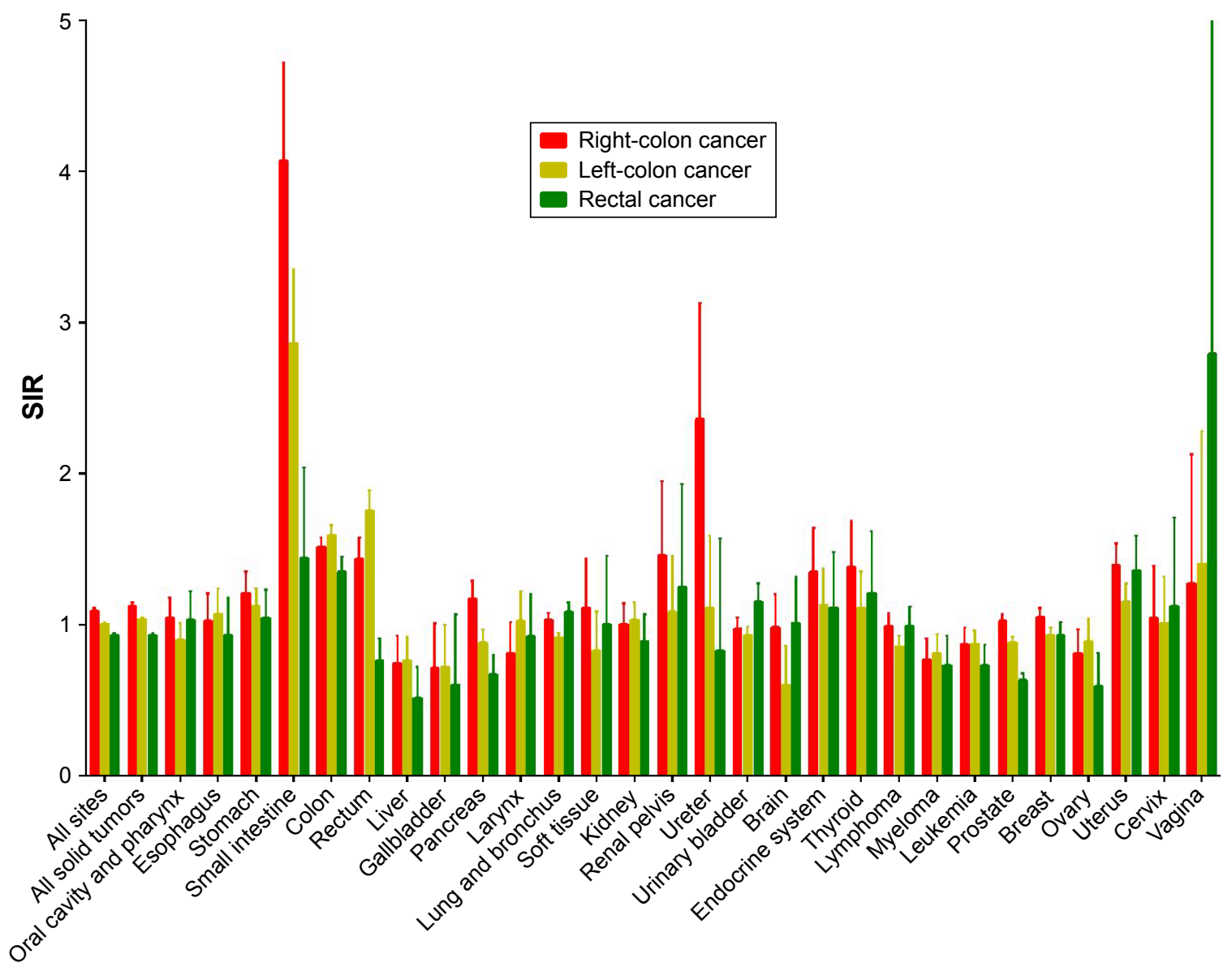

Figure 5 Risk varied by subsites of prior colorectal cancer for subsequent primary malignancies in different sites.

Notes: An inverse relationship was indicated between overall SIR and subsites of primary diagnosis: 1.09 in right-sided colon cancer, I in left-sided colon cancer, and 0.93 in rectal cancer. Patients with different prior colorectal cancer subsites showed specific sites at high cancer risk.

Abbreviation: SIR, standardized incidence interval.

brain, as well as myeloma and lymphoma, especially in old patients. The sites with increased cancer risk identified in the present study are included in the screening strategy for hereditary CRC. This relationship indicates that multiple malignancies subsequent to $\mathrm{CRC}$ and hereditary CRC may be derived from a common entity. Evidence for such a hypothesis was provided by a recent study based on the long-term follow-up of twins, in which the heritability risk was reported to be $15 \%$ and $14 \%$ for colon and rectal cancer, respectively, consistent with the cumulative incidence of multiple PMs. ${ }^{25}$

Table 2 Risk of subsequent primary malignancies among colorectal cancer survivors stratified by sex, age, and prior tumor location

\begin{tabular}{|c|c|c|c|c|c|c|c|c|c|}
\hline \multirow[t]{2}{*}{ Sex } & \multirow{2}{*}{$\begin{array}{l}\text { Age } \\
\text { (years) }\end{array}$} & \multicolumn{2}{|c|}{ Right colon } & \multicolumn{2}{|l|}{ Left colon } & \multicolumn{2}{|l|}{ Rectum } & \multicolumn{2}{|c|}{ All prior tumor locations ${ }^{a}$} \\
\hline & & Observed & SIR $(95 \% \mathrm{CI})$ & Observed & SIR (95\% CI) & Observed & SIR $(95 \% \mathrm{CI})$ & Observed & SIR (95\% CI) \\
\hline \multirow[t]{3}{*}{ Male } & $<60$ & 435 & $2.01(I .82-2.21)$ & 440 & $1.75(1.59-1.93)$ & 461 & $1.49(1.36-1.63)$ & 1,366 & $1.73(1.64-1.82)$ \\
\hline & $\geq 60$ & $6,|8|$ & $1.03(I-1.06)$ & 6,213 & $0.95(0.93-0.97)$ & $5,|7|$ & $0.87(0.84-0.89)$ & 17,774 & $0.95(0.93-0.96)$ \\
\hline & Total & 6,616 & $1.07(1.04-1.09)$ & 6,653 & $0.98(0.96-1)$ & 5,632 & $0.9(0.87-0.92)$ & 19,140 & $0.98(0.97-0.99)$ \\
\hline \multirow[t]{3}{*}{ Female } & $<60$ & 419 & $2.26(1.94-2.62)$ & 443 & $1.72(1.56-1.88)$ & 314 & $1.4 \mid(1.26-1.57)$ & 1,198 & $1.77(1.67-1.87)$ \\
\hline & $\geq 60$ & 5,355 & $\mathrm{I} .07(\mathrm{I} .04-\mathrm{I} . \mathrm{I})$ & 4,099 & I.0I (0.98-1.04) & 3,096 & $1.02(0.98-1.05)$ & 12,709 & $1.04(1.02-1.05)$ \\
\hline & Total & 5,774 & $1.11(1.08-1.14)$ & 4,542 & $1.05(1.02-1.08)$ & 3,410 & $1.04(1.01-1.08)$ & 13,907 & $1.07(1.06-1.09)$ \\
\hline \multirow[t]{3}{*}{ Total } & $<60$ & 854 & $2.13(1.99-2.27)$ & 883 & $1.74(1.62-1.85)$ & 775 & $1.46(1.36-1.56)$ & 2,564 & $1.75(1.68-1.81)$ \\
\hline & $\geq 60$ & 11,536 & $1.05(1.03-1.07)$ & 10,312 & $0.97(0.95-0.99)$ & 8,267 & $0.92(0.9-0.94)$ & 30,483 & $0.98(0.97-0.99)$ \\
\hline & Total & 12,390 & $1.09(1.07-1.11)$ & 11,195 & I.0I (0.99-I.03) & 9,042 & $0.95(0.93-0.97)$ & 33,047 & $1.02(1.01-1.03)$ \\
\hline
\end{tabular}

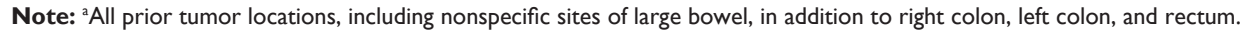

Abbreviations: SIR, standardized incidence ratio; $\mathrm{Cl}$, confidence interval. 
Most previous studies report a low incidence of hereditary CRC. Lynch syndrome, the most common hereditary malignancy, has an incidence of $1 \%$ and accounts for $2 \%-5 \%$ of all CRC cases, ${ }^{26,27}$ which is less than the cumulative incidence of multiple PMs. Hereditary CRC may be recognized as a typical representative group for multiple primary cancers. However, most patients with multiple primary cancers other than hereditary CRC differ from sporadic CRC patients regarding age. Further investigation is necessary to identify additional clinicopathological characteristics for differentiating these patients from all CRC patients.

A strong relation between $\mathrm{CRC}$ and urologic cancers was observed in a previous study. ${ }^{28}$ Among CRC patients, the risk was reported to increase for prostate and esophagus cancers in one study and for lung cancer in another study. ${ }^{13,29}$ The current study indicated an increased risk of cancers of the digestive system, urinary tract, and endocrine system in overall CRC patients, specifically for cancers of the respiratory system and genital system in women, whereas a similar or even reduced risk of malignancies of the nervous system and hematologic system was observed. Regarding cell derivation, epithelial tissues from all the systems at increased cancer risk were traced to stem cells from the embryonic endoderm, whereas systems with unchanged or reduced cancer risk stemmed from the ectoderm and mesoderm. This indicated a high concordance between the origin of tissue and sites where multiple PMs occurred. Because of this phenomenon, genetic susceptibility, a known risk factor for cancer, was considered the main pathogenetic factor in multiple PMs, especially genes with a high incidence of germ-line mutations, which play an important role in hereditary CRC.

CRC patients with genetic variations are at high risk of relative malignancies. Deficient mismatch repair or $B R C A 1$ and $B R C A 2$ variations were associated with increased risk of cancers of the colorectum, uterus, ovary, breast, stomach, and pancreas. MUTYH gene variation was associated with increased risk of colorectum, stomach, uterus, and breast cancers. EPCAM gene variation was associated with increased risk of gastric cancer. Many other genes, including SMAD4, STK11, BMPR1A, TPX, AURKA, and SEMA4A, were also reported to play important roles in the pathogenesis of multiple PMs. ${ }^{30-33}$ In addition to the genes listed, genome-sequencing technology has shown that germ-line mutations of POLE and POLDI are centralized in patients with multiple CRC and associated with endometrial cancer predisposition. ${ }^{34}$

The association between the risk of multiple PMs and the primary CRC subsite was reported previously in a study by Lee et al. ${ }^{11}$ These authors showed that the risk of thyroid, prostate, ovary, and hematological system cancers increased in patients with colon cancer, whereas patients with rectal cancer showed an increased risk of bone and soft-tissue cancers and a decreased risk of liver and gallbladder cancers. The present study confirmed the difference between patients with colon cancer and rectal cancer, and identified a difference between patients with right-sided and left-sided colon cancer. Studies have indicated that the risk for metachronous colorectal tumors is higher in patients with right-sided colon cancer than in those with left-sided colon cancer; ${ }^{16,35,36}$ however, other studies have indicated that patients with left-sided colon cancer have higher risk. ${ }^{37,38}$ Based on a detailed classification of primary CRC subsites in the present study, the risk of multiple primary cancers gradually decreased from patients with right-sided colon cancer to those with left-sided colon cancer and to rectal cancer. The overall risk of all SPMs increased in patients regardless of age and sex.

Moreover, patients with different prior CRC subsites had specific high-risk sites. Patients with right-sided colon cancer were at high risk of developing cancers of the small intestine, ureter, renal pelvis, colorectum, uterus, and thyroid, whereas patients with rectal cancer had higher risk of cancers of the vagina, bladder, and lung. In patients with left-sided colon cancer, the risk decreased for most cancers, except secondary primary CRC. These results suggest that attention should be paid to the specific sites at high cancer risk in each patient during follow-up. Cancers located in the right-sided colon have a high frequency of genetic variation in certain genes, including mismatch repair and $B R A F$, and these genes are associated with germ-line mutations. The high occurrence of multiple primary cancers in patients with right-sided colon cancer may be supported by the existence of such molecular changes.

A recent study found that cumulative radioactive iodine dose is predictive of all second PMs combined among thyroid cancer survivors. ${ }^{39}$ Davis et al also found that patients with prostate cancer who receive radiation are at high risk of developing bladder (SIR 1.42) and rectum (SIR 1.7) cancers. $^{15}$ Consistent with these studies, the present study showed that radiotherapy was associated with high cancer risk, especially for uterus and urinary bladder cancers (Table S1). This underscores the importance of protecting the pelvic organs during radiotherapy in patients with rectal cancer. In addition, risk of SPM was analyzed on year of diagnosis, race, SEER summary stage, and tumor grade (Tables S2-S5).

The present study had several limitations. First, detailed information on patient follow-up or specific recommendations 
for CRC surveillance was lacking, as well as specific advice regarding surveillance methods. Second, information on family history could not be obtained from the database, which made it difficult to screen patients with hereditary CRC. However, the incidence of hereditary CRC is low. The large sample size of the present study makes it representative of the entire population. Third, data on genetic variation was lacking, and direct comparisons at the molecular level were not possible. Detailed data on genetic variation are necessary to identify patients at high risk to perform individual surveillance in future studies.

In conclusion, based on a large sample size and long follow-up duration, the present population-based study showed that CRC survivors have an increased risk of developing multiple PMs, especially in the first 5 years after the initial CRC diagnosis and in young patients. The common sites at high risk of multiple PMs were primarily associated with tissues derived from the embryonic endoderm, including epithelial tissues of the digestive, urologic, endocrine, and female genital systems. Patients with different primary CRC subsites showed specific high-cancer-risk sites. These results suggest that genetic susceptibility is the main mechanism underlying multiple-cancer risk. Detailed information on genetic variation is necessary to identify patients at high risk of developing multiple primary cancers and to design individual surveillance programs.

\section{Disclosure}

The authors report no conflicts of interest in this work.

\section{References}

1. Chen W, Zheng R, Baade PD, et al. Cancer statistics in China, 2015. CA Cancer J Clin. 2016;66(2):115-132.

2. Kim B, Choi AR, Park SJ, et al. Long-term outcome and surveillance colonoscopy after successful endoscopic treatment of large sessile colorectal polyps. Yonsei Med J. 2016;57(5):1106-1114.

3. Moorcraft SY, Ladas G, Bowcock A, Chau I. Management of resectable colorectal lung metastases. Clin Exp Metastasis. 2016;33(3): 285-296.

4. Elez E, Argilés G, Tabernero J. First-line treatment of metastatic colorectal cancer: interpreting FIRE-3, PEAK, and CALGB/SWOG 80405. Curr Treat Options Oncol. 2015;16(11):52.

5. Das A, Chak A, Cooper GS. Temporal trend in relative risk of second primary colorectal cancer. Am J Gastroenterol. 2006;101(6):1342-1347.

6. Green RJ, Metlay JP, Propert K, et al. Surveillance for second primary colorectal cancer after adjuvant chemotherapy: an analysis of Intergroup 0089. Ann Intern Med. 2002;136(4):261-269.

7. Park IJ, Yu CS, Kim HC, Jung YH, Han KR, Kim JC. Metachronous colorectal cancer. Colorectal Dis. 2006;8(4):323-327.

8. Ballesté B, Bessa X, Piñol V, et al. Detection of metachronous neoplasms in colorectal cancer patients: identification of risk factors. Dis Colon Rectum. 2007;50(7):971-980.

9. Newton KF, Green K, Walsh S, Lalloo F, Hill J, Evans DG. Metachronous colorectal cancer risk in patients with a moderate family history. Colorectal Dis. 2013;15(3):309-316.
10. Cirillo L, Urso ED, Parrinello G, et al. High risk of rectal cancer and of metachronous colorectal cancer in probands of families fulfilling the Amsterdam criteria. Ann Surg. 2013;257(5):900-904.

11. Lee YT, Liu CJ, Hu YW, et al. Incidence of second primary malignancies following colorectal cancer: a distinct pattern of occurrence between colon and rectal cancers and association of co-morbidity with second primary malignancies in a population-based cohort of 98,876 patients in Taiwan. Medicine (Baltimore). 2015;94(26):e1079.

12. Liang YH, Shao YY, Chen HM, et al. Young patients with colorectal cancer haveincreasedrisk ofsecond primary cancers.JpnJClin Oncol.2015;45(11): $1029-1035$.

13. Lee JW, Kim JW, Kim NK. Clinical characteristics of colorectal cancer patients with a second primary cancer. Ann Coloproctol. 2014;30(1):18-22.

14. Kato T, Suzuki K, Muto Y, et al. Multiple primary malignancies involving primary sporadic colorectal cancer in Japan: incidence of gastric cancer with colorectal cancer patients may be higher than previously recognized. World J Surg Oncol. 2015;13:23.

15. Davis EJ, Beebe-Dimmer JL, Yee CL, Cooney KA. Risk of second primary tumors in men diagnosed with prostate cancer: a populationbased cohort study. Cancer. 2014;120(17):2735-2741.

16. Gervaz P, Bucher P, Neyroud-Caspar I, Soravia C, Morel P. Proximal location of colon cancer is a risk factor for development of metachronous colorectal cancer: a population-based study. Dis Colon Rectum. 2005; 48(2):227-232.

17. Cali RL, Pitsch RM, Thorson AG, et al. Cumulative incidence of metachronous colorectal cancer. Dis Colon Rectum. 1993;36(4):388-393.

18. Nelson R. Metachronous colorectal cancer and age. Colorectal Dis. 2006;8(9):812.

19. Shureiqi I, Cooksley CD, Morris J, Soliman AS, Levin B, Lippman SM. Effect of age on risk of second primary colorectal cancer. J Natl Cancer Inst. 2001;93(16):1264-1266.

20. Hemminki K, Li X, Dong C. Second primary cancers after sporadic and familial colorectal cancer. Cancer Epidemiol Biomarkers Prev. 2001;10(7):793-798.

21. Stoffel EM, Mangu PB, Gruber SB, et al. Hereditary colorectal cancer syndromes: American Society of Clinical Oncology clinical practice guideline endorsement of the familial risk - colorectal cancer: European Society for Medical Oncology clinical practice guidelines. J Clin Oncol. 2015;33(2):209-217.

22. Møller P, Seppälä T, Bernstein I, et al. Cancer incidence and survival in Lynch syndrome patients receiving colonoscopic and gynaecological surveillance: first report from the prospective Lynch syndrome database. Gut. Epub 2015 Dec 9.

23. Germini DE, Mader AM, Gomes LG, Teodoro TR, Franco MI, Waisberg J. Detection of DNA repair protein in colorectal cancer of patients up to 50 years old can increase the identification of Lynch syndrome? Tumour Biol. 2016;37(2):2757-2764

24. Casellas-Cabrera N, Díaz-Algorri Y, Carlo-Chévere VJ, et al. Risk of thyroid cancer among Caribbean Hispanic patients with familial adenomatous polyposis. Fam Cancer. 2016;15(2):267-274.

25. Mucci LA, Hjelmborg JB, Harris JR, et al. Familial risk and heritability of cancer among twins in Nordic countries. JAMA. 2016;315(1):68-76.

26. Siraj AK, Prabhakaran S, Bavi P, et al. Prevalence of Lynch syndrome in a Middle Eastern population with colorectal cancer. Cancer. 2015;121(11): 1762-1771.

27. Lynch HT, Boland CR, Gong G, et al. Phenotypic and genotypic heterogeneity in the Lynch syndrome: diagnostic, surveillance and management implications. Eur J Hum Genet. 2006;14(4):390-402.

28. Calderwood AH, Huo D, Rubin DT. Association between colorectal cancer and urologic cancers. Arch Intern Med. 2008;168(9):1003-1009.

29. Birgisson H, Wallin U, Holmberg L, Glimelius B. Survival endpoints in colorectal cancer and the effect of second primary other cancer on disease free survival. BMC Cancer. 2011;11:438.

30. Lu C, Xie M, Wendl MC, et al. Patterns and functional implications of rare germline variants across 12 cancer types. Nature Commun. $2015 ; 6: 10086$. 
31. Susswein LR, Marshall ML. Pathogenic and likely pathogenic variant prevalence among the first 10,000 patients referred for next-generation cancer panel testing. Genet Med. 2016;18(8):823-832.

32. Schulz E, Klampfl P, Holzapfel S, et al. Germline variants in the SEMA4A gene predispose to familial colorectal cancer type X. Nature Commun. 2014;5:5191.

33. Yun HR, Yi LJ, Cho YK, et al. Double primary malignancy in colorectal cancer patients: MSI is the useful marker for predicting double primary tumors. Int J Colorectal Dis. 2009;24(4):369-375.

34. Palles C, Cazier JB, Howarth KM, et al. Germline mutations affecting the proofreading domains of POLE and POLD1 predispose to colorectal adenomas and carcinomas. Nat Genet. 2013;45(2):136-144.

35. Lee TJ, Rees CJ, Blanks RG, et al. Colonoscopic factors associated with adenoma detection in a national colorectal cancer screening program. Endoscopy. 2014;46(3):203-211.
36. Yoshida N, Naito Y, Ho KT, et al. High incidence of metachronous advanced adenoma and cancer after endoscopic resection of colon polyps larger than or equal to $20 \mathrm{~mm}$ in size. Dig Endosc. 2015;28(2):1-9.

37. Rennert G, Robinson E, Rennert HS, Neugut AI. Clinical characteristics of metachronous colorectal tumors. Int J Cancer. 1995;60(6):743-747.

38. Borda A, Martínez-Peñuela JM, Borda F, Muñoz-Navas M, Jiménez FJ, Carretero C. Drawing up an individual risk index for development of metachronous neoplastic lesions in resected colorectal cancer. Rev Esp Enferm Dig. 2012;104(6):291-297.

39. Teng CJ, Hu YW, Chen SC, et al. Use of radioactive iodine for thyroid cancer and risk of second primary malignancy: a nationwide populationbased study. J Natl Cancer Inst. 2016;108(2):djv314. 


\section{Supplementary materials}

Table SI Risk of subsequent primary malignancies grouped by radiotherapy among patients with rectal cancer

\begin{tabular}{|c|c|c|c|c|c|c|}
\hline \multirow[t]{2}{*}{ Tumor site } & \multicolumn{2}{|c|}{ No radiation } & \multicolumn{2}{|l|}{ Radiation } & \multirow[t]{2}{*}{$P$-value ${ }^{a}$} & \multirow[t]{2}{*}{$\mathbf{O R}^{\mathbf{b}}$} \\
\hline & Observed & SIR (95\% CI) & Observed & SIR (95\% CI) & & \\
\hline All sites & 3,520 & $0.91(0.88-0.94)$ & 2,034 & $0.96(0.92-1.01)$ & 0.125 & \\
\hline All solid tumors & $3,|8|$ & $0.93(0.89-0.96)$ & $|, 82|$ & $0.97(0.92-1.01)$ & $<0.001$ & 1.04 \\
\hline Oropharynx & 87 & $0.99(0.79-1.22)$ & 55 & I.II (0.84-I.45) & 0.712 & \\
\hline Esophagus & 36 & $0.84(0.59-1.16)$ & 28 & $1.10(0.73-1.6)$ & 0.497 & \\
\hline Stomach & 88 & $0.99(0.79-1.22)$ & 49 & $1.17(0.87-1.55)$ & 0.606 & \\
\hline Small intestine & 15 & I.II (0.62-I.82) & 17 & $2.03(1.18-3.26)$ & 0.274 & \\
\hline Colon & 510 & $1.27(1.16-1.38)$ & 269 & $1.49(1.32-1.68)$ & 0.181 & \\
\hline Rectum & 63 & $0.68(0.52-0.87)$ & 42 & $0.92(0.66-1.24)$ & 0.284 & \\
\hline Liver & 17 & $0.48(0.28-0.77)$ & 14 & $0.56(0.31-0.94)$ & 0.825 & \\
\hline Gallbladder & 9 & $0.7(0.32-1.33)$ & 2 & $0.37(0.04-1.33)$ & 0.668 & \\
\hline Pancreas & 76 & $0.66(0.52-0.83)$ & 39 & $0.66(0.47-0.91)$ & 0.999 & \\
\hline Larynx & 26 & $0.72(0.47-1.06)$ & 26 & $1.29(0.84-1.89)$ & 0.173 & \\
\hline Lung and bronchus & 587 & $0.98(0.9-1.06)$ & 405 & $1.24(1.12-1.37)$ & 0.013 & 1.27 \\
\hline Soft tissue & 17 & $1.01(0.59-1.62)$ & 10 & $1.01(0.49-1.86)$ & 0.999 & \\
\hline Kidney & 77 & $0.96(0.76-1.2)$ & 40 & $0.76(0.54-1.04)$ & 0.363 & \\
\hline Renal pelvis & 14 & $1.32(0.72-2.22)$ & 6 & $1.14(0.42-2.48)$ & 0.999 & \\
\hline Ureter & 5 & $0.69(0.23-1.62)$ & 4 & I.II $(0.3-2.85)$ & 0.999 & \\
\hline Urinary bladder & 247 & $1.02(0.89-1.15)$ & 187 & $1.43(1.23-1.65)$ & 0.021 & $\mathrm{I} .4$ \\
\hline Brain & 37 & $1.09(0.77-1.5)$ & 18 & $0.91(0.54-1.44)$ & 0.69 & \\
\hline Endocrine system & 25 & $1.07(0.69-1.58)$ & 22 & $1.19(0.75-1.81)$ & 0.83 & \\
\hline Lymphoma & $15 \mid$ & $0.99(0.84-1.16)$ & 86 & $0.98(0.78-1.21)$ & 0.999 & \\
\hline Myeloma & 36 & $0.67(0.47-0.93)$ & 25 & $0.85(0.55-1.26)$ & 0.49 & \\
\hline Leukemia & 73 & $0.63(0.5-0.8)$ & 54 & $0.91(0.68-1.18)$ & 0.151 & \\
\hline Prostate & 590 & $0.77(0.7 \mathrm{I}-0.83)$ & 187 & $0.4(0.34-0.46)$ & $<0.001$ & 0.52 \\
\hline Breast & 355 & $0.96(0.86-1.07)$ & $15 \mid$ & $0.87(0.74-1.02)$ & 0.376 & \\
\hline Ovary & 23 & $0.54(0.34-0.81)$ & 14 & $0.72(0.39-1.21)$ & 0.513 & \\
\hline Uterus & 76 & $1.02(0.8-1.27)$ & 77 & $2.09(1.65-2.62)$ & 0.006 & 2.05 \\
\hline Cervix & 17 & $1.33(0.77-2.13)$ & 4 & $0.69(0.19-1.76)$ & 0.473 & \\
\hline Vagina & 4 & $1.45(0.4-3.72)$ & 7 & $6.09(2.45-12.45)$ & 0.282 & \\
\hline
\end{tabular}

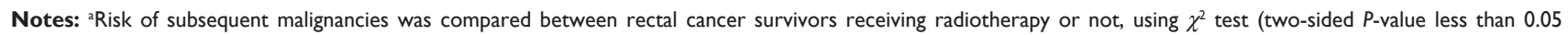
considered statistically significant); ' $\mathrm{OR}$ defined as ratio of SIR in radiation group to SIR in no radiation group.

Abbreviations: SIR, standardized incidence ratio; $\mathrm{Cl}$, confidence interval; OR, odds ratio.

Table S2 Risk of subsequent primary malignancies grouped by year of prior colorectal cancer diagnosis

\begin{tabular}{|c|c|c|c|c|c|c|}
\hline \multirow[t]{2}{*}{ Tumor site } & \multicolumn{2}{|l|}{$1973-1985$} & \multicolumn{2}{|l|}{$1986-1999$} & \multicolumn{2}{|l|}{$2000-2012$} \\
\hline & Observed & SIR (95\% CI) & Observed & SIR $(95 \% \mathrm{CI})$ & Observed & SIR (95\% CI) \\
\hline All sites & 4,277 & $1.05(1.02-1.08)$ & 13,840 & I.0I (0.99-1.03) & 14,930 & $1.02(1-1.03)$ \\
\hline All solid tumors & 3,975 & I.I (1.06-I.I3) & $|2,62|$ & $1.04(1.02-1.06)$ & 13,437 & $1.04(1.03-1.06)$ \\
\hline Oropharynx & 116 & $1.02(0.84-1.22)$ & 277 & $0.95(0.84-1.07)$ & 291 & I (0.88-I.I2) \\
\hline Esophagus & 40 & $0.95(0.68-1.3)$ & 124 & $0.89(0.74-1.06)$ & 203 & $1.19(1.03-1.37)$ \\
\hline Stomach & 112 & $0.91(0.75-1.1)$ & 375 & $1.2(1.08-1.32)$ & 349 & $1.2(1.08-1.34)$ \\
\hline Small intestine & 44 & $4.13(3-5.54)$ & 120 & $2.7 I(2.25-3.24)$ & 209 & $3.18(2.76-3.64)$ \\
\hline Colon & 865 & $1.69(1.58-1.8)$ & 2,233 & I.48 (I.42-I.54) & 1,990 & $1.49(1.43-1.56)$ \\
\hline Rectum & 197 & $1.54(1.34-1.78)$ & 378 & $1.15(1.04-1.28)$ & 512 & 1.75 (1.6-1.91) \\
\hline Liver & 17 & $0.65(0.38-1.04)$ & 60 & $0.58(0.44-0.74)$ & 143 & $0.79(0.67-0.94)$ \\
\hline Gallbladder & 13 & $0.66(0.35-1.12)$ & 27 & $0.6(0.39-0.87)$ & 36 & $0.79(0.55-1.09)$ \\
\hline Pancreas & 105 & $0.82(0.67-0.99)$ & 361 & $0.94(0.84-1.04)$ & 476 & $0.99(0.9-1.08)$ \\
\hline Larynx & 45 & $0.95(0.7-1.28)$ & 107 & $0.88(0.72-1.07)$ & 104 & $1.02(0.83-1.24)$ \\
\hline Lung and bronchus & 556 & $0.9(0.83-0.98)$ & I,977 & $0.97(0.93-1.01)$ & 2,313 & $1.02(0.98-1.06)$ \\
\hline Soft tissue & 10 & $0.67(0.32-1.24)$ & 49 & $0.92(0.68-1.22)$ & 82 & $1.06(0.84-1.31)$ \\
\hline
\end{tabular}

(Continued) 
Table S2 (Continued)

\begin{tabular}{|c|c|c|c|c|c|c|}
\hline \multirow[t]{2}{*}{ Tumor site } & \multicolumn{2}{|l|}{$1973-1985$} & \multicolumn{2}{|l|}{$1986-1999$} & \multicolumn{2}{|l|}{$2000-2012$} \\
\hline & Observed & SIR (95\% CI) & Observed & SIR (95\% CI) & Observed & SIR (95\% CI) \\
\hline Kidney & 73 & I.II (0.87-I.4) & 264 & $1.05(0.93-1.18)$ & 347 & $0.93(0.84-1.03)$ \\
\hline Renal pelvis & 17 & $1.37(0.8-2.19)$ & 40 & I.2(0.86-I.64) & 53 & $1.29(0.97-1.69)$ \\
\hline Ureter & 12 & I. $4(0.72-2.45)$ & 26 & I.I6 (0.75-I.69) & 49 & I.8I (1.34-2.39) \\
\hline Urinary bladder & 237 & I (0.87-I.I3) & 729 & $0.95(0.88-1.02)$ & 964 & $1.01(0.95-1.08)$ \\
\hline Brain & 25 & $0.69(0.45-1.02)$ & 113 & $0.98(0.8 \mathrm{I}-\mathrm{I} . \mathrm{I})$ & 101 & $0.78(0.64-0.95)$ \\
\hline Endocrine system & 28 & $1.39(0.92-2.01)$ & 62 & $0.95(0.73-1.22)$ & 173 & I.3 (I.II-I.5) \\
\hline Lymphoma & 116 & $0.89(0.74-1.07)$ & 483 & $0.96(0.88-1.05)$ & 615 & $0.9(0.83-0.97)$ \\
\hline Myeloma & 45 & $0.82(0.6-I . I)$ & 154 & $0.83(0.7 \mathrm{I}-0.98)$ & 165 & $0.73(0.62-0.85)$ \\
\hline Leukemia & 93 & $0.75(0.6-0.91)$ & 340 & $0.9(0.8-1)$ & 379 & $0.82(0.74-0.9)$ \\
\hline Prostate & 589 & $0.94(0.87-1.02)$ & 2,483 & $0.88(0.85-0.92)$ & 2,134 & $0.84(0.8 \mathrm{I}-0.88)$ \\
\hline Breast & 410 & I $(0.91-1.1)$ & $\mathrm{I}, 445$ & $1.01(0.96-1.07)$ & 1,402 & $0.94(0.89-0.99)$ \\
\hline Ovary & 84 & $1.44(1.15-1.79)$ & 142 & $0.83(0.7-0.98)$ & 101 & $0.59(0.48-0.7 I)$ \\
\hline Uterus & $|3|$ & $1.16(0.97-1.38)$ & 387 & $1.33(1.2-1.47)$ & 372 & $1.26(1.14-1.4)$ \\
\hline Cervix & 25 & $0.94(0.61-1.38)$ & 56 & I.07 (0.8I-I.39) & 40 & $\mathrm{I} .03(0.74-\mathrm{I} .4 \mathrm{I})$ \\
\hline Vagina & 6 & I.52 (0.56-3.3I) & 14 & $\mathrm{I} .32(0.72-2.2 \mathrm{I})$ & 21 & $1.74(1.08-2.66)$ \\
\hline
\end{tabular}

Abbreviations: SIR, standardized incidence ratio; $\mathrm{Cl}$, confidence interval.

Table S3 Risk of subsequent primary malignancies grouped by race among patients with prior colorectal cancer

\begin{tabular}{|c|c|c|c|c|c|c|c|c|}
\hline \multirow[t]{2}{*}{ Tumor site } & \multicolumn{2}{|l|}{ White } & \multicolumn{2}{|l|}{ Black } & \multicolumn{2}{|l|}{ Other } & \multicolumn{2}{|l|}{ Unknown } \\
\hline & Observed & SIR (95\% CI) & Observed & SIR (95\% CI) & Observed & SIR (95\% CI) & Observed & SIR (95\% CI) \\
\hline All sites & 28,531 & I (0.99-I.0I) & 2,401 & I.II (I.07-I.16) & 2,108 & $1.21(1.16-1.26)$ & 7 & $0.08(0.03-0.17)$ \\
\hline All solid tumors & 25,874 & $1.03(1.02-1.04)$ & 2,220 & 1.14 (I.I-I.19) & 1,932 & $1.24(1.18-1.29)$ & 7 & $0.1(0.04-0.2)$ \\
\hline Oropharynx & 590 & $0.95(0.88-1.03)$ & 30 & $0.75(0.5-1.07)$ & 64 & $1.68(1.3-2.15)$ & 0 & $0(0-1.96)$ \\
\hline Esophagus & 316 & $1.05(0.94-1.17)$ & 32 & $1.02(0.7-1.45)$ & 19 & I $(0.6-1.56)$ & 0 & $0(0-4.11)$ \\
\hline Stomach & 621 & $1.11(1.02-1.2)$ & 78 & $1.16(0.91-1.44)$ & 137 & 1.41 (1.19-1.67) & 0 & $0(0-2.47)$ \\
\hline Small intestine & 305 & $2.99(2.66-3.34)$ & 49 & $3.88(2.87-5.13)$ & 19 & $3.36(2.02-5.25)$ & 0 & $0(0-11.48)$ \\
\hline Colon & 4,454 & I.5। (I.47-I.56) & 343 & I.57 (I.4-I.74) & 289 & $1.62(1.44-1.82)$ & 2 & $0.25(0.03-0.92)$ \\
\hline Rectum & 892 & I.36 (I.27-I.45) & 103 & $2.55(2.08-3.09)$ & 92 & $1.85(1.49-2.27)$ & 0 & $0(0-2.03)$ \\
\hline Liver & 144 & $0.64(0.54-0.76)$ & 21 & $0.75(0.46-1.15)$ & 55 & $0.96(0.72-1.25)$ & 0 & $0(0-5.03)$ \\
\hline Gallbladder & 61 & $0.65(0.5-0.83)$ & 8 & I. $2(0.52-2.37)$ & 7 & $0.68(0.27-1.4)$ & 0 & $0(0-|4.2|)$ \\
\hline Pancreas & 793 & $0.94(0.87-1)$ & 77 & $0.96(0.76-1.2)$ & 72 & $1.09(0.85-1.37)$ & 0 & $0(0-1.5)$ \\
\hline Larynx & 226 & $0.97(0.84-I . I)$ & 21 & $0.84(0.52-1.28)$ & 9 & $0.85(0.39-1.61)$ & 0 & $0(0-5.46)$ \\
\hline Lung and bronchus & 4,175 & $0.97(0.95-1)$ & 376 & $1.04(0.94-I .15)$ & 294 & $1.09(0.97-1.23)$ & I & $0.08(0-0.45)$ \\
\hline Soft tissue & 122 & $0.95(0.79-1.14)$ & 11 & $1.3(0.65-2.32)$ & 8 & $0.91(0.39-1.79)$ & 0 & $0(0-9.31)$ \\
\hline Kidney & 586 & $0.98(0.9-1.06)$ & 60 & $1.13(0.86-1.45)$ & 38 & $1.07(0.75-1.46)$ & 0 & $0(0-1.94)$ \\
\hline Renal pelvis & 97 & $1.23(I-1.5)$ & 5 & $1.73(0.56-4.04)$ & 8 & $\mathrm{I} .66(0.72-3.27)$ & 0 & $0(0-16.44)$ \\
\hline Ureter & 78 & $1.49(1.18-1.86)$ & 2 & $1.32(0.16-4.78)$ & 7 & $1.68(0.68-3.46)$ & 0 & $0(0-25.38)$ \\
\hline Urinary bladder & I,764 & $0.97(0.93-1.02)$ & 80 & $1.19(0.94-1.48)$ & 86 & $1.24(0.99-1.53)$ & 0 & $0(0-0.72)$ \\
\hline Brain & 218 & $0.84(0.73-0.96)$ & 12 & $1.17(0.6 \mathrm{I}-2.05)$ & 9 & $0.88(0.4-1.66)$ & 0 & $0(0-4.53)$ \\
\hline Endocrine system & 218 & $0.84(0.73-0.97)$ & 13 & $1.17(0.6 \mathrm{I}-2.06)$ & 9 & $0.88(0.4-1.67)$ & 0 & $0(0-4.54)$ \\
\hline Lymphoma & $\mathrm{I}, 083$ & $0.91(0.86-0.96)$ & 49 & $0.97(0.72-1.29)$ & 82 & I.II (0.88-I.37) & 0 & $0(0-1.02)$ \\
\hline Myeloma & 290 & $0.75(0.67-0.84)$ & 53 & $0.93(0.7-1.21)$ & 21 & $0.94(0.58-1.43)$ & 0 & $0(0-3.27)$ \\
\hline Leukemia & 731 & $0.83(0.77-0.89)$ & 38 & $0.83(0.59-1.14)$ & 43 & $1.2(0.87-1.62)$ & 0 & $0(0-1.46)$ \\
\hline Prostate & 4,333 & $0.84(0.82-0.87)$ & 533 & $1.05(0.96-1.14)$ & 337 & $1.04(0.94-1.16)$ & 3 & $0.22(0.04-0.64)$ \\
\hline Breast & 2,903 & $0.98(0.95-1.02)$ & 202 & $0.95(0.82-1.09)$ & 151 & $1.04(0.88-1.22)$ & I & $0.1(0-0.58)$ \\
\hline Ovary & 289 & $0.8(0.7 \mid-0.9)$ & 15 & $0.67(0.37-1.1)$ & 23 & $\mathrm{I} .4 \mathrm{I}(0.89-2.1 \mathrm{I})$ & 0 & $0(0-3.14)$ \\
\hline Uterus & 776 & $1.25(1.16-1.34)$ & 51 & $1.16(0.86-1.53)$ & 63 & $2.24(1.72-2.87)$ & 0 & $0(0-I .72)$ \\
\hline Cervix & 89 & I $(0.8-\mid .23)$ & 19 & $1.03(0.62-1.6)$ & 13 & I.3। (0.7-2.23) & 0 & $0(0-12.19)$ \\
\hline Vagina & 36 & $1.59(1.11-2.2)$ & 2 & $0.72(0.09-2.59)$ & 3 & $2.6(0.54-7.6)$ & 0 & $0(0-52.94)$ \\
\hline
\end{tabular}

Abbreviations: SIR, standardized incidence ratio; $\mathrm{Cl}$, confidence interval. 
Table S4 Risk of subsequent primary malignancies grouped by SEER summary stage of prior colorectal cancer

\begin{tabular}{|c|c|c|c|c|c|c|c|c|}
\hline \multirow[t]{2}{*}{ Tumor site } & \multicolumn{2}{|l|}{ Localized } & \multicolumn{2}{|l|}{ Regional } & \multicolumn{2}{|l|}{ Distant } & \multicolumn{2}{|l|}{ Unstaged } \\
\hline & Observed & SIR (95\% CI) & Observed & SIR (95\% CI) & Observed & SIR $(95 \% \mathrm{CI})$ & Observed & SIR (95\% CI) \\
\hline All sites & 15,444 & I (0.99-I.02) & 15,525 & $1.04(1.02-1.06)$ & 1,208 & $0.98(0.92-1.03)$ & 870 & $0.96(0.9-1.02)$ \\
\hline All solid tumors & 13,955 & $1.03(1.01-1.04)$ & 14,153 & $1.07(1.06-1.09)$ & 1,138 & I.04 (0.98-I.I) & 787 & $0.98(0.92-1.05)$ \\
\hline Oropharynx & 322 & $0.98(0.88-1.09)$ & 313 & $0.98(0.87-1.09)$ & 33 & I.IS (0.79-I.6I) & 16 & $0.79(0.45-1.28)$ \\
\hline Esophagus & 173 & $1.03(0.89-1.2)$ & 165 & $1.02(0.87-1.19)$ & 13 & $0.94(0.5-1.6 I)$ & 16 & $1.62(0.93-2.63)$ \\
\hline Stomach & 416 & $1.2(1.09-1.32)$ & 368 & I.II (I-I.23) & 25 & $0.94(0.61-1.39)$ & 27 & $1.23(0.8 \mathrm{I}-1.79)$ \\
\hline Small intestine & 126 & $2.21(1.84-2.63)$ & 209 & $3.74(3.25-4.29)$ & 29 & $6.22(4.16-8.93)$ & 9 & $2.84(1.3-5.39)$ \\
\hline Colon & 2,278 & $1.42(1.36-1.48)$ & 2,460 & $1.61(1.54-1.67)$ & 215 & I.82(1.58-2.08) & 135 & $1.37(1.15-1.63)$ \\
\hline Rectum & 461 & $1.3(1.18-1.42)$ & 525 & $1.54(|.4|-1.67)$ & 69 & $2.42(1.88-3.06)$ & 32 & $1.45(0.99-2.04)$ \\
\hline Liver & 105 & $0.72(0.59-0.87)$ & 102 & $0.7 I(0.58-0.86)$ & 10 & $0.78(0.37-1.44)$ & 3 & $0.39(0.08-1.14)$ \\
\hline Gallbladder & 42 & $0.79(0.57-1.07)$ & 33 & $0.65(0.45-0.91)$ & 0 & $0(0-0.95)$ & I & $0.31(0.01-1.73)$ \\
\hline Pancreas & 413 & $0.87(0.79-0.96)$ & 474 & $1.04(0.95-1.14)$ & 31 & $0.86(0.59-1.22)$ & 24 & $0.87(0.56-1.29)$ \\
\hline Larynx & 118 & $0.93(0.77-I .1 I)$ & 121 & $0.98(0.81-1.17)$ & 5 & $0.43(0.14-1.01)$ & 12 & $1.47(0.76-2.56)$ \\
\hline Lung and bronchus & 2,244 & $0.96(0.92-1)$ & 2,331 & $1.03(0.99-1.07)$ & 158 & $0.84(0.7 \mathrm{I}-0.98)$ & 113 & $0.83(0.68-1)$ \\
\hline Soft tissue & 57 & $0.82(0.62-1.07)$ & 74 & I.I (0.87-I.39) & 4 & $0.73(0.2-1.87)$ & 6 & $1.54(0.56-3.35)$ \\
\hline Kidney & 324 & I (0.89-I.II) & 321 & I.0I (0.9-I.I2) & 24 & $0.86(0.55-1.28)$ & 15 & $0.83(0.46-1.37)$ \\
\hline Renal pelvis & 55 & $1.32(0.99-1.7 \mid)$ & 51 & $1.29(0.96-1.7)$ & 2 & $0.65(0.08-2.35)$ & 2 & $0.82(0.1-2.98)$ \\
\hline Ureter & 29 & $1.03(0.69-1.49)$ & 52 & $1.97(1.47-2.58)$ & 3 & $1.46(0.3-4.27)$ & 3 & $1.84(0.38-5.37)$ \\
\hline Urinary bladder & 928 & $0.98(0.92-1.04)$ & 880 & $0.99(0.93-1.06)$ & 61 & $0.88(0.67-1.13)$ & 61 & I.I (0.84-I.4I) \\
\hline Brain & 129 & $0.98(0.81-1.16)$ & 101 & $0.78(0.63-0.95)$ & 3 & $0.27(0.06-0.78)$ & 6 & $0.79(0.29-1.72)$ \\
\hline Endocrine system & 117 & $1.18(0.98-1.41)$ & 127 & $1.22(1.02-1.45)$ & 15 & $\mathrm{I} .45(0.8 \mathrm{I}-2.39)$ & 4 & $0.77(0.21-1.97)$ \\
\hline Lymphoma & 602 & $0.96(0.88-1.04)$ & 551 & $0.91(0.83-0.99)$ & 27 & $0.55(0.37-0.8 I)$ & 34 & $0.98(0.68-1.37)$ \\
\hline Myeloma & 179 & $0.81(0.69-0.94)$ & 162 & $0.76(0.64-0.88)$ & 13 & $0.74(0.39-1.27)$ & 10 & $0.77(0.37-I .4 I)$ \\
\hline Leukemia & 393 & $0.85(0.76-0.93)$ & 383 & $0.87(0.78-0.96)$ & 17 & $0.49(0.29-0.79)$ & 19 & $0.69(0.42-1.08)$ \\
\hline Prostate & 2,584 & $0.91(0.87-0.94)$ & 2,299 & $0.85(0.8 \mathrm{I}-0.88)$ & 186 & $0.78(0.67-0.9)$ & 137 & $0.78(0.66-0.93)$ \\
\hline Breast & I,532 & I (0.95-I.05) & 1,550 & $0.98(0.94-1.04)$ & 106 & $0.82(0.67-0.99)$ & 69 & $0.82(0.63-1.03)$ \\
\hline Ovary & 134 & $0.72(0.6-0.85)$ & 160 & $0.85(0.72-0.99)$ & 22 & $1.44(0.9-2.19)$ & II & $1.05(0.53-1.88)$ \\
\hline Uterus & 397 & $1.24(1.12-1.37)$ & 435 & $1.32(1.19-1.45)$ & 37 & $1.29(0.91-1.78)$ & 21 & I.I5 (0.7I-I.75) \\
\hline Cervix & 51 & $0.96(0.72-1.26)$ & 60 & $1.07(0.82-1.38)$ & 9 & $1.72(0.79-3.27)$ & I & $0.28(0.0 \mathrm{I}-\mathrm{I} .58)$ \\
\hline Vagina & 15 & $1.2(0.67-1.98)$ & 21 & $1.68(1.04-2.57)$ & 3 & $3.14(0.65-9.18)$ & 2 & $2.75(0.33-9.94)$ \\
\hline
\end{tabular}

Abbreviations: SEER, Surveillance, Epidemiology, and End Results; SIR, standardized incidence ratio; Cl, confidence interval. 


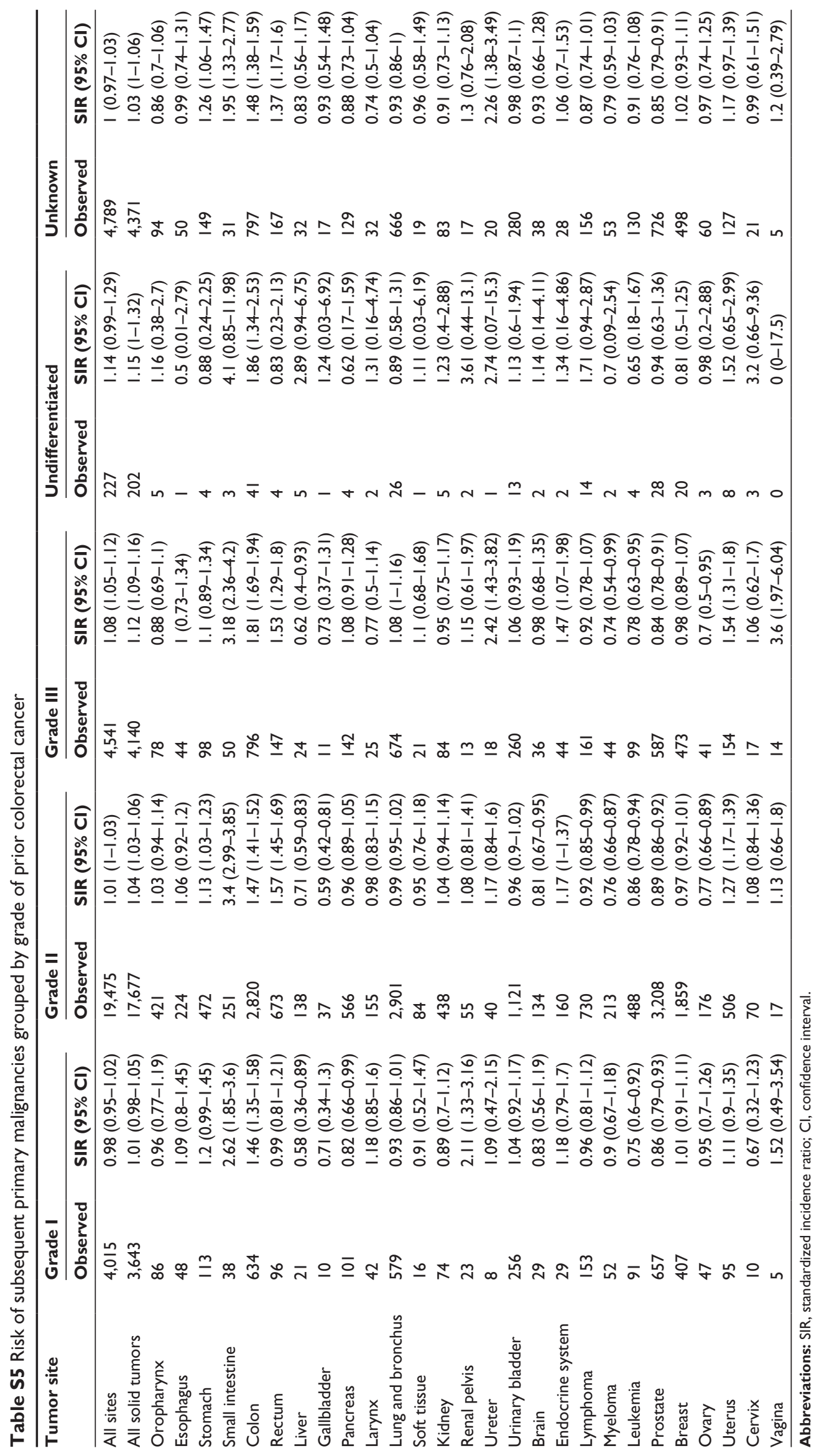




\section{Publish your work in this journal}

OncoTargets and Therapy is an international, peer-reviewed, open access journal focusing on the pathological basis of all cancers, potential targets for therapy and treatment protocols employed to improve the management of cancer patients. The journal also focuses on the impact of management programs and new therapeutic agents and protocols on

patient perspectives such as quality of life, adherence and satisfaction. The manuscript management system is completely online and includes a very quick and fair peer-review system, which is all easy to use. Visit http://www.dovepress.com/testimonials.php to read real quotes from published authors.

Submit your manuscript here: http://www.dovepress.com/oncotargets-and-therapy-journal 